\title{
Letter to the Editor: In Response
}

J Gen Intern Med 36(10):3239

DOI: $10.1007 / \mathrm{s} 11606-021-07060-5$

(C) Society of General Internal Medicine 2021

$\mathrm{T}_{\mathrm{w}}$ o the editor:

We wish to thank Muñoz-Price et al. [1] for their response to our article. We validate the conclusion of their study: poverty, not race, accounts for increased risk of severe COVID-19 disease. Socioeconomic status (SES) plays a crucial role in the severity of disease among minority populations. The pandemic has importantly magnified the health and healthcare disparities in the USA, exposing the underlying systems of inequity that produce them. Detroit and Milwaukee are cities that can be generalized to a national and global level.

In Detroit, over one-third of its 700,000 residents live under the poverty line [2]. This is a poverty rate which is nearly three times the national average [3]. Approximately $88 \%$ of persons experiencing homelessness in Detroit are African American [4]. As described by Muñoz-Price et al., regardless of SES, African Americans were more likely to test positive for the virus than persons of another race [1]. In the USA, racial minorities are more likely to have lower wage jobs, and more likely to work in "essential services" or in frontline occupations including healthcare support systems, public transportation, grocery stores, and food handling [5]. Issues with job stability may affect health insurance, and they may forgo testing and treatment of disease due to fears about costs, and inability to take time away from work [6]. In addition, there may be a general mistrust of the healthcare system due to historical and continuous racially motivated discriminatory practices and institutional biases [7]. They could lack access to a car and need to use public transportation, increasing the risk of acquiring COVID-19 [5].

We must acknowledge that these differences in health are a result of the unequal distribution of resources and power, which excluded people of color long ago. This institutionalized racism produces the very vulnerability that renders populations such as African Americans susceptible to the poor health outcomes of the COVID-19 pandemic. We must concede that numerous events in history rooted in systemic institutionalized racism and persisting today have led to the

Received June 20, 2021

Accepted July 20, 2021

Published online August 6, 2021 disproportionate chronic health problems among minority communities, especially among African Americans. As history has taught us, the most vulnerable populations will inevitably be more heavily affected by disease. The healthcare community has been quietly calling out for help for populations made vulnerable for years, but now is the time to shout for a call to action. If we, the medical community, do not demand and provoke change around structural and institutional racism, socioeconomic disparities, and their relationship with healthcare and disease, how can we stop the loss of these valuable lives that matter?

Anita Shallal, $M D^{1}$

Ijeoma Nnodim Opara, $M D^{2}$

Marcus Zervos, $M D^{1}$

${ }^{1}$ Department of Internal Medicine, Division of Infectious Diseases, Henry Ford Hospital,

Detroit, MI, USA

${ }^{2}$ Department of Internal Medicine, Division of Internal Medicine-Pediatrics, Wayne State University School of Medicine,

Detroit, MI, USA

Corresponding Author: Marcus Zervos, MD; Department of Internal Medicine, Division of Infectious Diseases, Henry Ford Hospital, Detroit, MI, USA (e-mail: mzervos1@hfhs.org).

\section{REFERENCES}

1. Muñoz-Price LS, Nattinger AB, Rivera F, et al. Racial disparities in incidence and outcomes among patients with COVID-19. JAMA Netw Open 2020;3(9):e2021892.

2. Data USA. COVID-19 in Numbers: Detroit, MI. Available at: https:// datausa.io/profile/geo/detroit-mi/. Accessed June 6, 2021.

3. Northeast Ohio Coalition for the Homeless. Poorest cities in the United States 2011. Available at: https://www.neoch.org/top-poorest-cities-in-us. Accessed June 6, 2021.

4. Homeless Action Network of Detroit. Available at: https://www.handetroit. org/reports. Accessed June 6, 2021.

5. Institute of Medicine. Unequal treatment: confronting racial and ethnic disparities in health care. Washington, DC: National Academies Press; 2003.

6. Artiga S, Garfield R, Orgera K. Communities of color at higher risk for health and economic challenges due to COVID-19. 2020. Available at: https: / / www.kff.org/disparities-policy/issue-brief/ communities-of-color-at-higher-risk-for-health-and-economic-challenges-due-to-covid-19/. Accessed June 6, 2021.

7. Boulware LE, Cooper LA, Ratner LE, LaVesit TA, Powe NR. Race and trust in the health care system. Public Health Rep 2003;118:358-65.

Publisher's Note: Springer Nature remains neutral with regard to jurisdictional claims in published maps and institutional affiliations. 